\title{
Motivation and Challenges of Married Emirati Students in Teacher Education
}

\author{
Lilly Tennant, Patricia Stringer, and Sumaya Saqr
}

Emirates College for Advanced Education, Abu Dhabi, United Arab Emirates

Email Addresses: Itennant@ecae.ac.ae,gpstring@ihug.co.nz,ssaqr@ecae.ac.ae

Received: 3 Jun. 2013, Revised: 15 Jun. 2012, Accepted: 30 Jun. 2013

Abstract: This article provides an insight into the issues married female Emirati students face in pursuit of a Bachelor of Education (B.Ed) teaching degree from the perspective of the United Arab Emirates (UAE) context. Their views reflect their experiences in a landscape of educational reform and social change. Using a survey instrument, the perceptions of 102 married female Emirati students were examined in relation to: motivational factors underpinning their decision to pursue their teaching degree; challenges encountered during the course of their study; support strategies used to mitigate and alleviate challenges encountered; and future possibilities for support. For the married female Emirati student participating in this study, a confluence of social factors account for their desire to pursue and attain their B. Ed teaching degree. These and aspects of challenges and support are traceable to spheres of influence encompassing self, family, college, society and culture. It is important that these insights are investigated and the data analyzed when constructing programs that have implications for teacher education in the context of the UAE.

Keywords: Emirati, Married, United Arab Emirates, Teacher Education, Motivation, Challenges, Supports

\section{INTRODUCTION}

The UAE is passing through a period of rapid change and transformation to become a knowledge-driven economy capable of sustaining high standards of living and a secure way of life (Aswad, Vidican \& Samulewicz, 2011; Sowa \& De La Vega, 2008; Crabtree, 2007). Education is seen as the primary means of achieving modernization without, as His Highness Sheikh Khalifa bin Zayed Al Nahayan (President of the UAE) cautions, "distorting tradition in such a way that the existence of the homeland, the identity of the citizen, and the solidarity of society are maintained" (Al-Faisal, 1999, p. 13). Rapid change and transformation of the UAE has occurred in all sectors: economic, social and educational. According to Macpherson, Kachelhoffer and El Nemr (2007), the reforms exhibit an indigenous and neo-pluralist theory of modernization that gives simultaneous priority to four meta -values: 1) a strong and diversified economy; 2) full and successful involvement in the ICT revolution; 3) an open Arabic and Islamic knowledge society; and 4) an educational system of international character and quality (p. 62).

This study is embedded in the context of educational change in the emirate of Abu Dhabi where educational reforms have been initiated by the Abu Dhabi Education Council (ADEC), a non federal government authority established in September, 2005. Translation of aforementioned modernization points by the Ministry of Education into reform initiatives, produced nine priorities identified as: developing learning criteria suitable for the UAE to meet international standards; adopting student-focused learning environments; devolution of responsibility and accountability to schools; integration of ICT to enhance learning and management; rebuilding and refurnishing schools; staff development; boosting investment and accountability in creating successful schools; ensuring private schools offer safe and legal environments and quality for value; and offering adult literacy pathways to higher education, technical training and continuous learning (Macpherson et al., 2007, p. 63). In keeping with these priorities, the development of an Emirati teacher pool capable of delivering a modern curriculum in public schools lists high on the agenda. This paper is based on a study that considers married female Emirati students' pursuit of a B. Ed teaching degree with 
regard to: motivational factors underpinning enrolment in the degree; challenges faced during the course of study; support strategies used to mitigate and alleviate challenges encountered; and future possibilities for support.

\section{LITERATURE REVIEW}

In line with the aims, the literature reviewed covers: Emirati women in higher education, the changing role of women in the family setting, and the educational reform agenda and the impact of this on teacher training and teacher trainees.

\section{Emirati Women in Higher Education}

Women's entry into higher education has consistently increased over the past two decades (UNESCO, 2009) and is considered essential and necessary for the construction of a new society (Ayad al-Qazzat, 2003). Al Marzouqi and Nick (2011) describe the events taking place as a, "quiet revolution" in the legal rights and economic power of Emirati women. The stimulus for UAE women's development has largely been through access to education strongly promoted by UAE Government scholarship programs (Ministry of State for Federal National Council Affairs, 2009; Crabtree 2007). Based on the UNDP report of 2007, the number of UAE national women enrolled in higher education is actually 24 percent more than the number of UAE national men. According to a Pricewater House Coopers report discussed at the Arab Youth Forum in Dubai (2005), at 77 percent "the UAE is registering the highest rate of females in higher education in the entire world" 1 .

Despite efforts to increase women's participation in education training aligned with high-status professional fields (for example, science, technology and engineering), women and men continue to be concentrated in different occupations (Aswad, Vidican \& Samulewicz, 2011). In response to a survey that questioned 750 UAE residents titled: Which gender is better suited for what careereducation and the culinary arts were favored by women whereas engineering, architecture and law ranked high for men (Arab Pulse Program, $\mathrm{Al}$ Alan TV, The National, Saturday May 4 th 2013). According to Salem (2011), the career most widely cited by Arab women including Emiratis is teaching (79\%) followed by medicine and then nursing. Some factors influencing this choice include working in predominantly female environments, hours conducive to family life and fostering the patriotic spirit of imparting knowledge to the younger generation (Salem, 2011). Yang's (2002) study showed that UAE nationals found that public sector (e.g., teaching in public schools) employment is considered a very favorable option for most female Emiratis.

One tool used to measure the factors that influence women's occupational role is 'The Eccles' Model' (Eccles, 1984). The model states that decisions women make in relation to occupational choice relate to "gender role beliefs, to self-perceptions and self-concept and to one's perceptions of the task itself” (Eccles, 1994, p. 587). With regard to gender differences in occupations linked to math and science, women are less likely to enter these areas than men because they have less confidence in their abilities and place less subjective value on these fields than on 'other' possible occupations (Eccles, 1994). Furthermore, gendered socialization practices "at home, in the schools, and among peers play a major role in shaping these individual differences in self-perceptions and subjective task values" (p. 605). Although previously mentioned statistics show an increase in women's involve ment in higher education, this does not assume gains made translate to the workplace, academe and society. As noted by Lindsey (2012), Arab women say they are still questioned and criticized for pursuing careers rather than marriage; women's studies, voices and views are largely marginalized. 


\section{Family Life in the UAE}

Traditionally the UAE society, as part of the wider Arab Muslim world, has been characterized by close interpersonal relationships. The individual has a network of close ties including the nuclear family, relatives and close neighbors. The traditional socialization process emphasizes obedience, closeness and loyalty to parents rather than independence and self-reliance. The UAE society is strongly influenced by religion and culture, especially in respect to women's role in society (Erogul \& McCrohan, 2008). Aswad et al. (2011) notes that in the Arab culture of the UAE with, "a family -based patriarchal society with clearly defined gender roles, the aspect of parental influence on educational choice is expected to be more pronounced" (p. 561). In line with this, Baud and Mahgoub (2001) note that restrictions placed on women in terms of geographic mobility limits their options in terms of access to education and acceptable employment.

Immediate and extended members of the Emirati family provide networks of support; that is, the culture of close knit family ties that exists in the UAE society means that the extended family plays a role in supporting working mothers (Baud and Mahgoub, 2001). In addition, household help is also available and as RoudiFahimi and Moghadam (2004) note, this is a critical factor related to decisions whether to work or not. Baud and Mahgoub (2001) assert that the ready availability of household help (in the form of young female immigrants) facilitates Emirati women's labor force participation; an important feature of the UAE labor market that serves to facilitate women's employment.

Although the family remains one of the highest influences on decisions women make regarding education and career choices (Aswad, Vidican \& Samulewicz, 2011), exposure to modernization, different value sets, living styles and social change are starting to play a larger influence on women's roles in society. Personal inclination and individualism draw to the surface tensions and challenges associated with the changing role of women in society and their fulfillment of multiple roles and responsibilities in connection with family and study/work commitments.

\section{The Educational Reform Agenda: Impact on Teacher Training and Teacher Trainees}

The educational landscape in Abu Dhabi is a shifting dynamic; one focused on change and reform of the schooling system. In response to calls for modernization, ADEC's Strategic Plan for the 2009-2018 period focuses on six key priorities: 1) elevate school quality in Abu Dhabi to international standards; 2) improve access to P-12 education; 3) provide students with affordable options of high quality private education; 4) preserve UAE culture and heritage and develop successful careers; 5) build ADEC capabilities; and 6) actively engage the stakeholders (ADEC, 2009). As part of implementing change, ADEC introduced the New School Model in September, 2010 which Dr. Al Khaili states has a focus “on students' performances and treats them as free thinkers and independent learners via applying the concept of 'whole child philosophy’ (El Ajou, 2010).

Educational change is rapid in Abu Dhabi and represents a shift from the traditional format of memorization, repetition and discipline based on physical punishment to a more innovative pedagogy and student centered pedagogy (Sowa \& De La Vega, 2009). Familiarization with new pedagogies, content knowledge and skills associated with the New School Model, delivery of the core curriculum (science and math) in English, working alongside licensed teachers (predominantly native speakers of English) as interns in schools form components of the B. Ed. teaching degree designed to prepare Emirati teacher trainees to teach in schools. It is hoped that the influx of Emirati novice teachers in schools will graduate Emirati youth with strong academic backgrounds and proficient bilingual skills (Sowa \& De La Vega, 2009). The ability of Emirati teacher trainees to succeed and thrive as potential teachers in an environment of educational and social change necessitates an examination of the particular challenges they encounter during their course of studies and their ability to enact support by way of alleviation and mitigation.

Teaching is a demanding and complex profession (Al Mahrooqi \& Al Hashmi, 2012). Birjandi \& Hesari (2010) claim it is "an amalgamation of principles, processes, skills strategies, behaviors, beliefs, perceptions, and attitudes all of which could have great impacts on teaching and learning” (p. 50). Students training to be 
teachers at colleges in the UAE are exposed to different pedagogical approaches embedded within a predominantly Western paradigm as evidenced in the New School Model. They experience 'new ways of doing things' when mixing with lecturers from different countries delivering the curriculum in English. Such influences produce a contestation of values.

Although a focus on values does not directly form part of this exploratory study, it is important to recognize that value debates through interaction with 'others' may present themselves as challenges which need solutions in terms of: How do married female Emirati students cope with challenges of context? Further, how can higher educational institutions support this group to successfully complete their degrees?

This exploratory study was guided by determinants of a shifting context from traditional to progressive attitudes and practices in education. The purpose was to examine, at the microsystem college level, the social, cultural and economic motivational forces that foster enrolment in the B. Ed. teaching degree, challenges faced during the course of study, support strategies utilized to mitigate and alleviate challenges of context and future support possibilities that may lead to the college adjusting their systems, structures and processes in support of married female Emirati students undertaking teacher degree programs.

\section{RESEARCH METHODOLOGY}

The setting for this research is a teacher training college in Abu Dhabi, UAE. The college is not affiliated to any particular university and is licensed and accredited by the Commission for Academic Accreditation, and the Ministry of Higher Education and Scientific Research. It offers a four-year Bachelor of Education teaching degree through English as the medium of instruction. Aligned with the New School Model, Emirati students are prepared to teach a range of subjects including math and science. The college offers a one-year Foundation studies program for students who do not fulfill the Bachelor of Education program entry requirements.

This exploratory study encompasses both quantitative and qualitative research methods. Data collection tools included a questionnaire, semi structured interviews, and a focus group discussion. For the purpose of this paper, quantitative findings of the data collected through questionnaires distributed online to married female students are presented. The questionnaire was used as to investigate: 1) motivational factors accounting for pursuit of a B. Ed teaching degree; 2) challenges faced in the course of undertaking the degree; 3) support strategies utilized to mitigate and alleviate challenges; and 4) future possibilities of support that would assist students complete their degrees.

\section{Participants of the Study}

The study involved married female Emirati students enrolled in the B. Ed teaching degree program across all four year groupings at the college (Table 1). The total number of students enrolled in the college at the time of the study was 400 and of these, 121 were married. From a combined pool of 121 married students, 102 agreed to participate and complete the questionnaire. About $60 \%$ of the married students were between the ages of 20-24years and 40\% were 25 years and above. All participants were full time students not otherwise employed.

Table 1: Participants in the B. Ed program

$\begin{array}{cc}\text { B. Ed Year level Number of } & \\ \text { Respondents \% of Respondents } \\ \text { Y ear 1 } & 2222.45 \\ \text { Y ear 2 } & 2020.41 \\ \text { Y ear 3 } & 0707.14 \\ \text { Y ear 4 } & 4950.00 \\ \text { Not mentioned } & 04\end{array}$




\section{Questionnaire}

The conceptual framework that underpinned the construction of the questionnaire was Bronfenbrenner's ecological systems theory (Bronfenbrenner, 1979) and a review of the literature to identify issues of a sociocultural nature relevant to women. Bronfenbrenner highlights five socially organized subsystems that support and guide human development: microsystem; mesosystem; exosystem; macrosystem; and chronosystem. In keeping with Bronfenbrenner's theory, the questionnaire sought to examine sources of motivation, challenges, support strategies and future support possibilities associated with the various levels of: microsystem, mesosystem, exosystem and macrosystem. The questionnaire was divided into five sections: demographic information; motivational factors; challenges; supports strategies utilized; and future possibilities of support. The questionnaire was translated into Arabic by a legal translator. The final version of on-line survey included both English and the Arabic versions.

To ensure validity and reliability, the questionnaire was piloted with 38 married female B.Ed. students from three different higher educational institutions in Abu Dhabi. Stringent ethical protocols were followed in the administration of the pilot questionnaire. For example, the researchers contacted administrators from the various institutions to gain entry to their students for feedback on the draft questionnaire. Once permission was granted, the questionnaire was given to the administrators who then invited students to complete the questionnaire and provide feedback on: 1) missing or incorrect demographic items; 2) language used in item construction; 3) items considered ambiguous or in need of further clarification; 4) items that were missing and/or redundant; 5) ease of administration; and 6) time taken to complete the questionnaire. Respondents' data from the pilot survey were entered into an electronic file for analysis of reliability and trustworthiness of items in terms of internal consistency. The Cronbach's alpha coefficie nt of reliability for the question items in the survey was 0.814 which indicates a high level of internal consistency.

The final survey questionnaire consisted of forty five items. Utilizing the eSurveysPro software package, a selection of formats that best suited the type of information desired was constructed. These included: single select questions with responses; multiple select questions; free form text-unlimited responses where respondents may enter as much text as they want; numeric value items requiring respondents to enter a numeric value within a specified range; and utilization of a matrix where groups of questions had the same response five-point Likert scale of strongly agree, agree, neutral, disagree, and strongly disagree. At the end of each section, provision was made for written comments.

Administratively, the database of married female Emirati students was obtained from the college. The research team approached these students and shared the intent of the research study and invited them to participate. During the four weeks of data collection, interested participants completed the questionnaire at their convenience. Participants provided written consent prior to completing the questionnaire.

The survey data was entered into the eSurveysPro online software and responses tabulated electronically. Using descriptive statistics such as means and percentages, quantitative data was analyzed. Statistics were calculated for all questionnaire sections and subsections. The qualitative data was classified into themes according to the various sections.

\section{FINDINGS}

Understanding the contexts shaping female married Emirati women's choice to pursue and complete their degree is pivotal to supporting their participation in the degree program. The findings presented point to motivational sources, challenges, support strategies and future support possibilities. 
Table 2: Motivating factors (percentages)

\begin{tabular}{|c|c|c|c|c|c|}
\hline $\begin{array}{l}\text { I am pursuing the college degree for the } \\
\text { following reasons: }\end{array}$ & $\begin{array}{c}\text { Strongly } \\
\text { Agree }\end{array}$ & Agree & Neutral & Disagree & $\begin{array}{l}\text { Strongly } \\
\text { Disagree }\end{array}$ \\
\hline 1. To be an educated parent & . & & & & \\
\hline $\begin{array}{l}\text { 2. Add to my knowledge and } \\
\text { experience }\end{array}$ & $\cdot .1$ & & & & \\
\hline $\begin{array}{l}\text { 3. To be an active member in society } \\
\text { and honor my country }\end{array}$ & & & & & \\
\hline 4. Increase my self confidence & 1. . & .10 & & & \\
\hline $\begin{array}{l}\text { 5. Teaching is a desirable occupation } \\
\text { for women in my culture }\end{array}$ & 2. . & 1.0 & & & \\
\hline 6. Improve my financial situation & 1.21 & & & & \\
\hline 7. Peer encouragement & 1. . & & & & \\
\hline
\end{tabular}

\section{Motivating Factors}

Regarding motivational factors, as shown in Table 2, the majority of participants (89\%) strongly agreed that being an educated parent is the highest motivational factor encouraging them to pursue their $\mathrm{B}$. Ed. teaching degree. Next, 84\% strongly agreed that their motivation stemmed from a desire to extend their knowledge and experience capabilities. Over 82\% strongly agreed that being a teacher meant they could contribute to society and honor their country. Over $75 \%$ of the married students mentioned that enrolment in this degree program had increased their self confidence, while $46 \%$ strongly agreed that teaching is a desirable occupation for women in their culture. Financial reasons were indicated by $45 \%$ as reasons for pursuing this course of study. Qualitative statements corresponding to the above include: "to be a role model for my children"; "empower myself and acquire the skills and knowledge to be in the working field"; "to fulfill my dream and my mother's dream to complete my college education and aspire to reach the top level in education"; and "to have a secure life and be prepared for problems or challenges". Peer encouragement accounted for $45 \%$ strongly agreeing that this was another motivational factor to pursue enrolment in the degree.

\section{Challenges}

Table 3: Challenges faced by married female Emirati students (percentages)

The challenges that I face are: Strongly

\section{FAMILY}

Agree Agree Neutra l $\quad$ e Disagree

1. Spending less quality time with my children $53.57 \quad 30.95 \quad 10.71 \quad 4.76 \quad 0$

2. Spending less time with relatives and sharing the social life 52.7535 .164 .407 .690

3. Spending less quality time with my husband

4. Difficulty meeting family and study commitments 39.1345 .6511 .963 .260

5. My extended family members (including husband's) do not offer support $17.05 \quad 17.05 \quad 20.45 \quad 30.68 \quad 14.77$

\section{COLLEGE}

1. Too many courses and assignments per semester and inflexible deadlines

2. Lack of facilities on campus: (e.g. child care nursery, lounge, study area) 21. 
3. College Policies: attendance, course time table, maternity leave)

1. student issues

5. Teaching and Learning in English is a challenge

6. College faculty not understanding family situation

$\begin{array}{llllll}1.21 & .1 & 16.30 & 4.35 & 2.17 \\ .1 & .1 & 10.87 & 8.70 & 6.52 \\ .1 & 2.2 & 17.39 & 11.96 & 2.17\end{array}$

\section{SOCIETY \& CULTURE}

1. My choice of employment in terms of location is limited to working in close proximity to my home

2. Family identifies me as a married person first and student second 50.0025 .00

3. My employment opportunities are limited to a female only school environment

$9.78 \quad 13.04 \quad 2.17$

$\begin{array}{llll}.1 & . & 12.0912 .091 .10\end{array}$

Table 3 reflects participants' views on the challenges faced during their course of study. The findings are presented according to family, college, society and cultural contexts.

\section{Family}

In the Emirati community, family gatherings, weddings and regular visits to extended families are integral to family life. Overall, figures representing the strongly agreed category related to family aspects as challenges include the following: 53\% commented that spending less quality time with their children was challenging; $52 \%$ claimed that spending less quality time with relatives and missing out on shared social life was a challenge; 50\% responded that being a student meant having less quality time with their spouse; 39\% found it hard to juggle family and study commitments. They said they were not fulfilling their role as wife, mother and daughter/daughter in-law; $17 \%$ claimed that their extended family members did not offer support and this posed a challenge in terms of child care. Qualitative responses in connection include: "I have difficulty coordinating between teaching my children and my learning all day long at the college and the increasing load of being a mother"; "As a mother of two special needs children I need more time to take care of them”; and "My husband's mother and family do not understand my educational commitments".

College

The college is a new teacher education institution and employs a more structured approach to course delivery. For example, new enrollments commence in September, the beginning of the academic year, and are required to follow the sequence of courses and credits as stated. Over $70 \%$ strongly agreed that the number of courses, limited flexibility to choose pathways based on need and too many assignments per semester were challenging. Comments in support were, "Our college system does not allow a student to withdraw one semester if needed" and "the college system is set up in a way that I cannot take one course because I have a new baby”.

Over 65\% strongly agreed and 19\% agreed that the college lacked facilities which limited its potential to service students' needs. In this regard they mentioned the need for a nursery. Over $59 \%$ strongly agreed that college policies related to maternity leave presented challenges. Following the birth of a child, students are allowed two weeks maternity leave and this was considered too short and not appropriate. Over $45 \%$ strongly agreed they needed qualified counselors to assist them solve issues of a personal nature. In the college, delivery of the curriculum occurs in the medium of English and in this regard, 44\% strongly agreed that learning in the English language was a challenge for all students whose first language is Arabic. In relation to 
college staff not understanding the home circumstances and family obligations of the married student, $31 \%$ strongly agreed that this was a challenge.

Society and culture

As married female Emirati students poised to enter the workforce, prospects for future employment was important. In this respect, over 56\% strongly agreed that proximity to their home was essential for cultural reasons but this limited their choice to what was available. The next area of tension faced was the duality of role fulfillment faced as wife a nd mother balanced with that of student. Over $50 \%$ strongly agreed that their family rated their married role greater status than that of student. Over $47 \%$ strongly agreed that their employment opportunities were limited to a female only school environment denoting adherence to cultural protocols. Corresponding qualitative comments include: "the number of working hours in the education sector are so long and as a mother and teacher I am affected as I will get back home late"; "in my family teaching is an accepted profession but my biggest ambition is to find a profession other than teaching even though teaching has helped me understand about schools and how to teach children different subjects”.

\section{Support systems}

Participants were asked to complete the demographic section in the questionnaire detailing types of family support available to them during their course of study. An analysis of the data indicates four main categories of support: financial; child care; home management; and emotional. In terms of financial support, participants said they received $40 \%$ assistance from their spouse; $16 \%$ from their fathers; $11 \%$ from their mothers; $10 \%$ from their brothers and the rest from extended family members. In terms of child care, $26 \%$ mentioned that their mothers assisted with child care duties. Mothers also provided emotional and moral support. Mothers-in-law and husbands contributed 18\% each as far as child care was concerned and assistance from sisters worked out to $11 \%$. Other members of the family provided minimal assistance. In terms of home management, data revealed married students could avail various forms of domestic help: 54\% reported that they had a housemaid; $25 \%$ had a driver; while nannies, cooks and gardeners were categorized as 'other' services available. Home management extended to help received from family members: $26 \%$ related to spouse, $20 \%$ to mother-in-law input; $19 \%$ to the mother and the rest was spread among siblings. In terms of emotional support, data revealed that $18 \%$ was received from mothers, $17 \%$ from the spouse, $12 \%$ from fathers and $12 \%$ from sisters. Other extended family members (brothers, uncles and aunts) contributed lesser amounts of emotional support.

Additional to family support networks, data revealed that government financial support was provided to meet the cost of higher education. All students at the college received a monthly stipend which extended throughout their academic years of study. However, only $27 \%$ strongly agreed that they benefitted from this amount of government financial support.

\section{Future Support Possibilities}

Employment as teachers in public schools was raised by students in terms of future possibilities. Over 43\% strongly agreed that opportunities would be made available for them to be future teachers in the public schools. Over $48 \%$ strongly agreed that obtaining a teacher education degree would offer them better opportunities for career advancement. In terms of future support, changes to college policies were noted as important. For example, over $67 \%$ wanted policies to take into consideration the needs of married students. Possibilities for future support also included the need to provide alternative pathways for course delivery. For example, 50\% expressed the need for distance education and a blend of online and face to face mode of curriculum delivery. Students' comments were positive in terms of undertaking their B. Ed teaching degree. Comments in favor included: "I chose to complete my education because I love to study"; and "I have to enter into society to be a contributing individual and to give back the kind act of our father and leader late Sheikh Zayed Al Nahyan and his encouragement to women’s education”. 


\section{DISCUSSION}

This research study examined the views of married female Emirati students in relation to motivating factors, challenges, support strategies and future possibilities of support. A discussion of insights on issues raised is presented next.

Students were asked to identify the main reasons behind their choice to enroll in this degree. The findings point to perceptions of the teaching profession as culturally appropriate based on gender stereotypes. From the Emirati cultural perspective, the teaching profession is highly valued as a desirable occupation for women (Arab Pulse Program, Al Alan TV, The National, Saturday May 4 th 2013; Salem, 2011; Yang, 2002). Even though Emirati women are encouraged to work in mixed gender environments, there are still certain tribes that hold fast to traditional beliefs of women working in female only environments (Al Mazroui, 2012). In this study, participants confirmed this link as a very important cultural expectation for females and, as such, a motivational factor.

Apart from gender related influences, UAE women are also limited in their career and occupational choices as certain occupations, outside of the usual gender biases, are considered inappropriate or undesirable for Emirati (Roudi-Fahimi \& Moghadam, 2004). For example, Emiratis do not prefer personal service occupations, such as many of those in the hotel industry, waitressing and hairdressing. This makes teaching, as a profession, all the more desirable for Emirati women.

The findings revealed that challenges were encountered at all levels: microsystem, mesosystem, exosystem and macrosystem (Bronfenbrenner, 1979). The main challenges focused on: balancing multiple role and responsibilities of being a wife, mother, daughter/daughter-in-law and fulltime student; and coping with college demands and social cultural community expectations in the area of managing work, study and home commitments.

There are various avenues of home management support available to female married Emirati students. In addition, the UAE government provides free higher education to their citizens to the Bachelor's degree level. These and other kinds of financial aid in the form of scholarships and stipends serve to alleviate previously mentioned challenges of context.

In many ways the data confirms not only the changing focus of women to pursue higher education and the growing need to be self educated but, also, an accompanying mismatch of present status, future goals and conflicting role delineation in the various spheres of influence - self, family, college, society and culture. The implications from the findings are profound in terms of understanding the social changes and the stresses encountered when fulfilling the requirements of a degree program.

\section{Future Implications}

In reviewing the findings of the questionnaire, there are certain implications specific to our college and a few for other higher education institutions. One of the recommendations is to offer courses with a more blended teaching approach rather than the traditional mode of face to face in-class teaching. Distance education or online courses are other options that could be offered to married students. Currently, the college academic calendar and the sequence of courses are very structured with little choice except that a student could withdraw from a course at any point in the semester but will have to wait another academic year for the course to be reoffered. This implies a need for flexible scheduling of college timetables.

At the college level there is a need for educators and administrators to cultivate cultural awareness about family role commitments married female students encounter during their course of study. A greater investment in establishing program flexibility, effective systems of communication in support and facilities such as child care and counselors could contribute towards successful completion of the degree. Hiring qualified counselors who understand the culture is essential for the provision of appropriate counseling services to all students and specifically when dealing with issues related to married students. Other services that would make the college a student friendly environment include provision of language support centers, quiet study areas, fitness centers, and lounges (traditional majilis). A more student centered approach could be adopted to meet the varying needs of students. Hence, it would be advisable for education policy makers 
at government and institutional levels to work closely to find suitable solutions in response to meeting emotional and educational needs of students.

\section{CONCLUSION}

The principle objective of this exploratory study was to examine the experiences of married female Emirati students undertaking their B. Ed. teaching degree to identify the motivational forces that foster enrolment, the challenges encountered during their course of study, the support strategies used to mitigate and alleviate challenges of context and possibilities for future support. Within the UAE context of reform and change and in the college setting, a number of unique challenges pointed to the need for programmatic flexibility and institutional support as reasonable and necessary to encourage and sustain this group of students' completion of their degree. Critical in the development of a knowledge-based economy fostering local capacity, is an Emirati pool of trained teachers delivering an international educational curriculum. This exploratory study opens up the need for further research on various related topics such as institutional barriers in sustainment of study as well as factors in support of married female Emirati students' pursuit of teacher education degrees.

\section{ACKNOWLEDGEMENT}

This research study was funded by the Emirates Foundation for Youth and Development, an independent, philanthropic organization set up by the Government of the Emirate of Abu Dhabi to facilitate public -private funded research initiatives to improve the welfare of people across the UAE.

\section{REFERENCES}

Abu Dhabi Education Council (2009). “ Abu Dhabi Education Council Strategic Plan for P-12 Education (2009-2018) Abu Dhabi”, Abu Dhabi Education Council, Abu Dhabi

Al- Awad, M., \& Elhiraika, A. (2002). "Skills, gender, nationality and income inequality in the United Arab Emirates”, Journal of Social Affairs , 19(76), 139-151.

Al-Faisal, T. (1999), Human resources and development in the Arabian gulf. The Emirates Center for Strategic Studies and Research . Abu Dhabi. 13-15.

Al Mahrooqi, R., \& and Al Hashmi, F. (2012). Beginning Omani EFL Teachers’ Perspectives on the Challenges they Encounter. Arab World English Journal, 3 (3), 190-203.

Al Marzouqi, A. H., \& Nick, F. (2011). An exploratory study of the under-representation of Emirate women in the United Arab Emirates information technology sector. Equality, Diversity and Inclusion: An International Journal ，30(2), 544-562.

Al Mazroui, A., (2012), Emirati women and work force in a clash of culture, The National , 19, May, p.3.

Al Qaazat A. (2003). Education of Women in the Arab World. Cornell University Library available at on www.cornell.library.edu/colldev/mideast/awomeduc.htm (accessed on April 10, 2012).

Aswad, N. G., Vidican, G., \& Samulewicz. (2011). Creating a knowledge-based economy in the United Arab Emirates: realizing the unfilled potential of women in the science, technology and engineering fields. European Journal of Engineering Education, 36(6), 559-570.

Baud, I., and Mahgoub, H.K., (2001), " Towards Increasing National Female Participation in the Labour Force ". Research Report 2, Centre for Labour Market Research and Information, Tanmia, Dubai

Birjandi, P., and Hesari, A. (2010). Teachers' pperceptions of the preset and optimum status of the in -service EFL teacher preparation programs. English Language Teaching. 3 (4), 47-57.

Bronfenbrenner, U. (1979). The Ecology of Human Development: Experiments by Nature and Design . Harvard University Press.

Crabtree, S. (2007). Culture, Gender and the influence of social change amongst Emirati families in the United Arab Emirates, Journal of Comparative Family Studies . 38(4), 575-587.

Dubai Consultancy, Research and Media Centre, (2009). Available at http://en.dubaiconsultancy.com/perspectives/admiring-the-path-of-emirati-women (accessed on 12 April 2013).

Eccles, J. S. (1987). Gender roles and women’s achievement-related decisions. P Psychology of Women Quarterly, 11 , 135172. 
Eccles, J. S., (1994). Understanding women’s educational and occupational choices. 585-609.

Psychology of Women Quarterly, 18 ,

El Ajou, N. (2010). “ ADEC launches New School Model to be implemented on all Abu Dhabi schools within 6 years available at http://www.a meinfo.com/242007.html (accessed 10 May 2012).

Erogul, M.S.,and McGrohan, D., (2008), “Preliminary investigation of Emirati women entrepreneurs in the UAE”, African Journal of Business Management, 10 (2), 177-185.

Lindsey, U. (2012). Arab Women Make Inroads In Higher Education but Often Find Dead Ends. Chronicle of Higher Education , 58(22), 12-14.

Macpherson, R., Kachelhoffer, P., and El Nemr, M. (2007). The Radical Modernization of School and Education System Leadership in the United Arab Emirates: Towards Indigenized and Educative Leadership. International Studies in Educational Administration, 35 (1), 60-77.

Ministry of State for Federal National Council Affairs (2009), Women in the United Arab Emirates: A Portrait of Progress. Ministry of State for Federal National Council Affairs, Abu Dhabi.

Roudi-Fahimi, F., \& Moghadam, M.V., (2004). " Empowering women, developing society: Female education in the Middle East and North Africa ", available at http://www.prb.org/Template.cfm?Section=PRB\&template=/Content

/ContentGroups/Rep. 1/18/2004, (accessed on May 15, 2013).

Salem, O. (2011). “Arab women want strong marriage over rights” ， The National, 9 April, p. 3.

Sean, (2012).“Nosy in-laws push up divorce rates”, 7 Days, 8 October, p.1.

Sowa, P., \& De La Vega, E. (2008).One Corner at a Time: Collaborating for Educational Change in the UAE. Association for Childhood Education International, 85 (2), 102-106.

UNDP, (2007). Millenium development goals: United Arab Emirates Report ， available at http://www.undp.org.ae/Upload/Doc/NMDGs_Eng2007_rec.pdf (accessed on 7 October 2012).

UNESCO, (2009). Global education digest: Comparing education statistics across the world. Paris: UNESCO.

Yang, G., (2002), " Retaining the UAE National Employees in the Private Sector: Findings of Two Surveys and Lessons to Human Resource Managers ", UAE National Labour Force Survey Series, No. 6, Centre for Labour Market Research and Information, Tanmia. 